\title{
DAMPAK EKONOMI PEMBERLAKUAN PERATURAN MENTERI KELAUTAN DAN PERIKANAN NO. 2 TAHUN 2015 TERHADAP AKTIVITAS USAHA NELAYAN CANTRANG DI KOTA PROBOLINGGO, JAWA TIMUR
}

\section{Economic Impact of Enforcement of Regulation of The Minister of Marine and Fisheries No. 22015 Operating Activities Against Fishermen in Probolinggo Cantrang, East Java}

\author{
*Siti Hajar Suryawati dan Radityo Pramoda \\ Pusat Penelitian Sosial Ekonomi Kelautan dan Perikanan \\ Gedung Balitbang KP I Lt. 4 \\ Jalan Pasir Putih Nomor 1 Ancol Timur, Jakarta Utara \\ Telp: (021) 64711583 Fax: 64700924r 2015 \\ *e-mail: siti_suryawati@yahoo.com \\ Diterima 12 April 2014- Disetujui 25 Mei 2015
}

\begin{abstract}
ABSTRAK
Penelitian ini bertujuan untuk mengetahui dampak ekonomi pemberlakukan Peraturan Menteri Kelautan dan Perikanan No. 2 Tahun 2015 terhadap aktivitas usaha nelayan cantrang di Kota Probolinggo, yang meliputi aspek pendapatan, kerugian asset usaha, modal usaha serta mekanisme pemasaran. Metode yang digunakan adalah analisis deskriptif dengan pendekatan Regulatory Impact Assessment (RIA). Data yang digunakan adalah data primer yang diambil pada bulan Mei 2015 dengan teknik wawancara, pencatatan, dan observasi di TPI Mayangan, Kota Probolinggo. Sampel responden diambil secara snowball sampling terhadap pemilik kapal, nakhoda, Anak Buah Kapal (ABK), pedagang, juru timbang, dan kuli angkut. Hasil penelitian menunjukan bahwa nelayan cantrang merupakan kelompok masyarakat yang paling banyak merasakan dampak pemberlakuan Permen KP No. 2 Tahun 2015. Mereka mengalami penurunan pendapatan, kerugian aset usaha yang sudah diinvestasikan, dan kredit macet ke bank. Penelitian dampak ekonomis dari pemberlakuan Permen KP No 2 Tahun 2015, diharapkan dapat dijadikan sebagai dasar pertimbangan implementasi permen tersebut sehingga nelayan cantrang juga tidak menanggung risiko terlalu besar.
\end{abstract}

Kata Kunci: permen KP No 2 tahun 2015, nelayan, cantrang, Kota Probolinggo

\begin{abstract}
The research aims to determine economic impact of implementation of the regulation of Minister of Marine and Fisheries No. 2 of 2015 in Probolinggo City, including revenue aspect, business assets losses aspect, capital aspect, and marketing mechanism. Method of analysis was descriptive analysis and regulatory impact assessments. The research collects primary data during May 2015 by interview techniques, recording and observation in TPI Mayangan, Probolinggo City. Research sample were vessel owners, skippers, crews, traders, interpreter stations, and porters. They taken by snowball sampling method. Results show that cantrang fishermen were group society that feel many impact of implementation of the regulation of Minister of Marine and Fisheries No. 2 of 2015. They experienced a decline in revenues, asset Losses effort is well invested, less credit to the bank. It can be expected as the fundamental basis for the Implementation ot the regulation that the risk of fishermen not too big.
\end{abstract}

Keywords: regulation of Minister of Marine and Fisheries No. 2 of 2015, fisherman, trawl, Probolinggo City 


\section{PENDAHULUAN}

Keputusan Presiden Nomor 39 Tahun 1980, tentang Penghapusan Jaring Trawl (Pukat Harimau) di Perairan Jawa, Sumatera, dan Bali, dibentuk dalam rangka menjaga kesehatan habitat serta produktivitas penangkapan nelayan tradisional.

Alat penangkapan ikan jenis trawl yang berkembang di masyarakat, banyak ditemukan dalam bentuk serta nama yang beragam (sifat penangkapannya tidak ramah lingkungan). Hal ini dikarenakan bersifat mengeruk dasar perairan dan menggunakan mata jaring yang kecil, sehingga sumber daya ikan yang masih anakan ikut tertangkap. Praktek penggunaan trawl di beberapa negara di dunia mengalami akibat buruk. Kondisi tersebut mengakibatkan FAO mengeluarkan aturan main, yang mengatur agar sumber daya ikan tetap terjaga melalui Code of Conduct for Responsible Fisheries (CCRF) (FAO, 1995).

Hasil modifikasi alat tangkap yang memiliki produktivitas tinggi dan cukup efektif dalam menangkap ikan dasar seperti trawl, salah satunya adalah cantrang. Cantrang merupakan alat tangkap yang memiliki tiga bagian utama, yaitu sayap, badan, dan kantong. Cantrang dioperasikan dengan cara ditarik di atas kapal yang tidak bergerak atau sedang berlabuh di perairan. Selain itu, dasar perairan daerah pengoperasian harus datar dan berlumpur atau berpasir (Bambang, 2006). Keputusan Menteri Kelautan dan Perikanan No. 45 Tahun 2011, tentang Estimasi Potensi Sumberdaya Ikan di Wilayah Pengelolaan Perikanan Negara Republik Indonesia, menyatakan bahwa status eksploitasi sumber daya ikan demersal sudah mencapai status eksploitasi lebih (fully exploited) (salah satunya disebabkan oleh Pukat Hela) seperti cantrang dan potensi sumber daya udang dalam status tangkap lebih (overfishing).

Upaya pemerintah memulihkan kembali daya dukung lingkungan tersebut adalah dengan mengesahkan Peraturan Menteri Kelautan dan Perikana Nomor 2 Tahun 2015, tentang Larangan Penggunaan Alat Penangkapan Ikan Pukat Hela (Trawls) dan Pukat Tarik (Seine
Nets) di Wilayah Pengelolaan Perikanan Negara Republik Indonesia (Permen KP No. 2/2015). Permen KP No. 2/2015, diberlakukan untuk mengatur penggunaan alat tangkap Pukat Hela dan Pukat Tarik, yang sudah menyebabkan menurunnya sumber daya ikan dan mengancam kelestarian lingkungan. Implikasi berlakunya Permen KP No. 2/2015, menyebabkan puluhan ribu nelayan tidak dapat melaut dan menangkap ikan karena menggunakan alat tangkap yang dilarang. Respon masyarakat nelayan terhadap pemberlakuan peraturan ini beragam. Di satu sisi, nelayan yang menggunakan alat tangkap yang dilarang menjadi resah dan melakukan penolakan. Pada sisi lain, nelayan yang tidak terkena pelarangan sangat mendukung kebijakan pemerintah ini. Kondisi ini sebagaimana yang digambarkan oleh (Bailey, 1988) dimana mereka memperebutkan ikan dari sumber yang sama, bahkan fishing ground yang sama.

Kota Probolinggo merupakan salah satu wilayah di Provinsi Jawa Timur yang sebagian nelayannya menggunakan alat tangkap cantrang. Nelayan cantrang di Kota Probolinggo sangat menolak pemberlakuan Permen KP No. 2/2015. Dasar penolakannya, karena mereka akan kehilangan sumber mata pencaharian. Untuk itu, kajian ini bertujuan untuk memberikan sumbangan pemikiran mengenai dampak pemberlakuan Permen KP No. 2/2015, terhadap aktivitas usaha nelayan yang menggunakan alat tangkap cantrang.

\section{METODE PENELITIAN}

\section{Lokasi dan Waktu Penelitian}

Kegiatan penelitian dilakukan pada bulan Mei 2015 di Kota Probolinggo, Provinsi Jawa Timur (Gambar 1). Kota Probolinggo dipilih, karena merupakan salah satu wilayah yang sebagian besar nelayannya terkena dampak pemberlakuan Permen KP No. 2/2015.

\section{Jenis dan Sumber Data}

Jenis data yang dikumpulkan adalah data primer dan sekunder. Menurut Marzuki (2002), data primer adalah data yang langsung diperoleh dari sumbernya. Data sekunder adalah data 


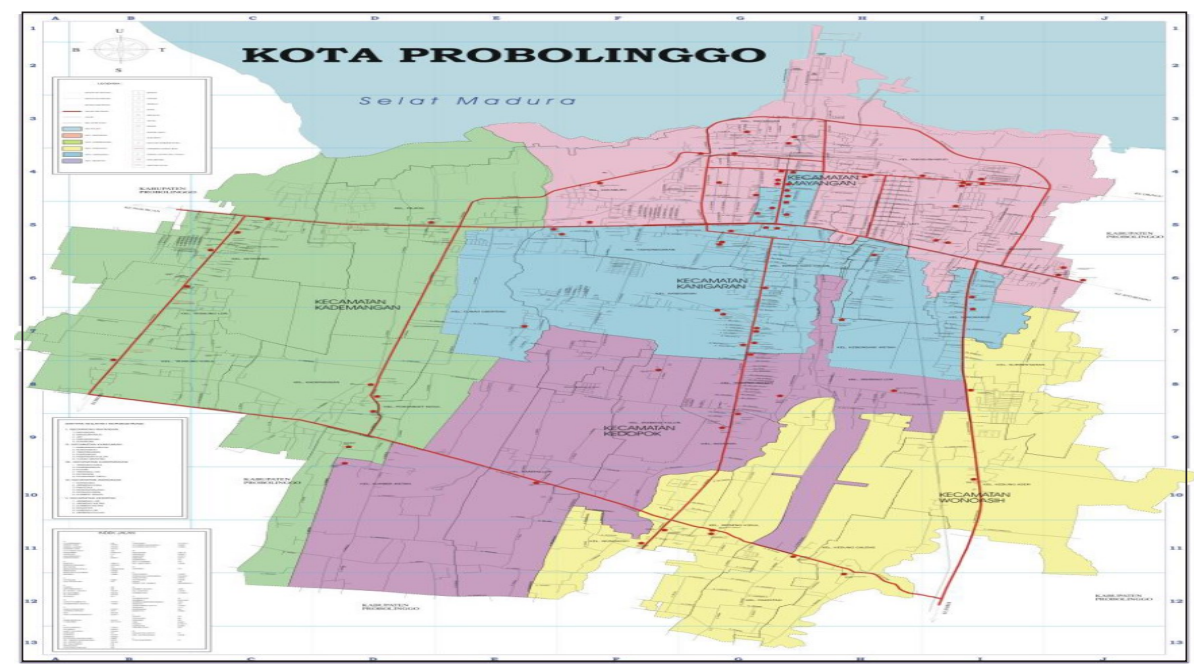

Gambar 1. Peta Wilayah Kota Probolinggo, Jawa Timur (BPS, 2013)

yang tidak langsung diperoleh dari sumbernya. Data sekunder yang dibutuhkan meliputi: jumlah produksi perikanan tangkap laut, jumlah kapal motor, statistik perikanan, Kota Probolinggo dalam Angka (BPS, 2013; BPS, 2014; BPS, 2015; BPS, 2016), dokumen, laporan, peraturan daerah, serta hasil penelitian yang mendukung pembahasan.

Pengumpulan data primer dilakukan melalui wawancara dengan responden nelayan menggunakan kuesioner. Observasi langsung juga dilakukan di lokasi penelitian, untuk mengetahui kegiatan usaha penangkapan ikan dengan alat tangkap cantrang di TPI (Tempat Pendaratan Ikan) Mayangan, Kota Probolinggo. Materi data primer yang diambil berkenaan dengan data usaha penangkapan menggunakan alat tangkap cantrang, serta respon terhadap pemberlakuan Permen KP No. 2/2015.

Penggalian informasi melalui teknik wawancara mendalam dilakukan, untuk menggali informasi secara terperinci menggunakan instrumen panduan pertanyaan (guideline questionaire). Wawancara dilakukan kepada: Kepala Dinas Kelautan dan Perikanan, Sekretaris Dinas Kelautan dan Perikanan, Kepala Bidang Pengawasan Sumberdaya Kelautan dan Perikanan, Kasie Konservasi, Kepala Tempat Pelelangan Ikan, Ketua HNSI, Kepala UPT Pengembangan Teknologi Penangkapan Ikan, dan pakar akademisi Universitas Brawidjaja, Malang.

\section{Metode Analisis Data}

Metode analisis yang digunakan dalam penelitian ini adalah metode deskriptif kualitatif dan kuantitatif. Metode ini dibutuhkan untuk melihat efektivitas biaya implikasi dari peraturan pemerintah. Tujuannya adalah untuk mengetahui setiap nilai rupiah biaya yang digunakan dalam kegiatan usaha dapat memberikan sejumlah nilai penerimaan sebagai manfaatnya. Dampak kebijakan pemberlakuan Permen KP No. 2/2015, dianalisis menggunakan pendekatan Regulatory Impact Analysis (RIA) yang dikembangkan oleh Badan Perencanaan dan Pembangunan Nasional [Bappenas] (2011).

\section{Kerangka Pendekatan Penelitian}

Pemberlakuan Permen KP No. 2/2015, pada dasarnya bertujuan memperbaiki kualitas sumber daya ikan dan daya dukung lingkungan perairan agar tercipta kelestarian yang berkelanjutan. Tujuan tersebut, dalam pelaksanaannya mendapat penolakan dari nelayan yang menggunakan alat tangkap yang dilarang. Secara ekonomi, mereka mengalami penurunan pendapatan, terancam kehilangan sumber mata pencaharian, dan terjerat hutang perbankan. Berdasarkan hal ini, kajian penelitian dilakukan dalam menganalisis dampak ditetapkannya Permen KP No. 2/2015, pada aktivitas usaha nelayan cantrang di Kabupaten Probolinggo dengan pendekatan RIA (Gambar2). 


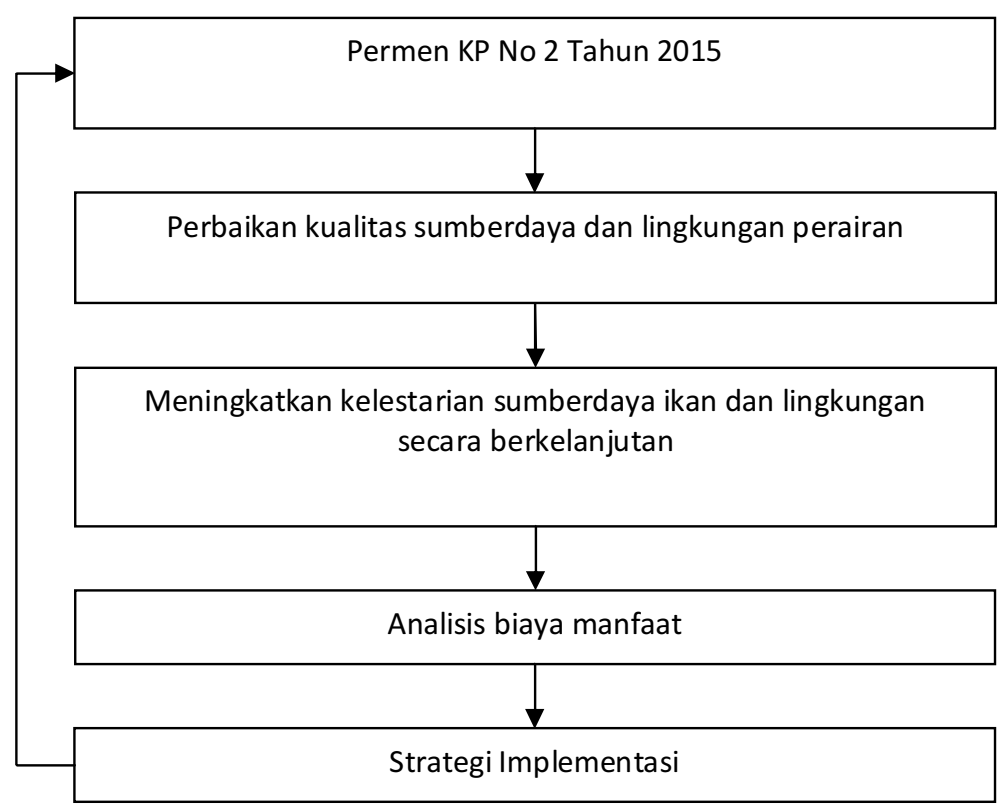

Gambar 2. Kerangka Pendekatan Penelitian Dampak Ekonomi Pemberlakuan Permen KP No. 2/2015 pada Nelayan Cantrang di Kota Probolinggo

\section{HASIL DAN PEMBAHASAN}

\section{Gambaran Umum Wilayah Penelitian}

Kota Probolinggo adalah salah satu kota yang terletak di Propinsi Jawa Timur diantara 38 Kabupaten/Kota lainnya. Letak Kota Probolinggo berada pada 7043'41"-7049'04" Lintang Selatan

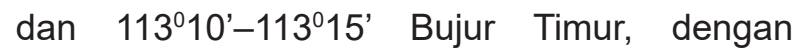
rata-rata ketinggian 10 meter di atas permukaan laut. Batas wilayah utara Kota Probolinggo, berbatasan dengan Selat Madura dan sebelah timur berbatasan dengan Kecamatan Dringu wilayah Kabupaten Probolinggo. Batas wilayah selatan berbatasan dengan Kecamatan Leces, Kecamatan Wonomerto, Kecamatan Bantaran dan Kecamatan Sumberasih (ketiganya masuk wilayah Kabupaten Probolinggo). Batas wilayah barat berbatasan dengan Kecamatan
Sumberasih wilayah Kabupaten Probolinggo. Luas Wilayah Kota Probolinggo 56,667 Km², terbagi menjadi 5 kecamatan dan 29 kelurahan (BPS, 2016).

Nelayan Kota Probolinggo yang paling banyak adalah nelayan tetap, selebihnya merupakan nelayan sambilan, andon dan kadang-kadang (Tabel 1). Produksi dan nilai produksi perikanan tangkaplautKota Probolinggo pada tahun 2010 sampai 2014 cukup fluktuatif (Tabel 2).

Produktivitas perikanan tangkap perlu mendapat dukungan sarana dan prasarana penangkapan, termasuk motorisasi kapal penangkapan. Jumlah kapal motor di Kota Probolinggo tahun 2010-2014, dapat dilihat pada Tabel 3.

Tabel 1. Jumlah Nelayan di Kota Probolinggo, Tahun 2010 - 2014.

\begin{tabular}{cccccc}
\hline \multirow{2}{*}{ No } & \multirow{2}{*}{ Tahun } & \multicolumn{4}{c}{ Jumlah Nelayan (orang)/Number of Fishermen (person) } \\
\cline { 3 - 6 } & & Tetap & Sambilan & Andon & Kadang-Kadang \\
\hline 1 & 2010 & 2.844 & 412 & 277 & 67 \\
2 & 2011 & 1.850 & 185 & 193 & 52 \\
3 & 2012 & 2.200 & 125 & 120 & 40 \\
4 & 2013 & 2.200 & 245 & 130 & 40 \\
5 & 2014 & 2.130 & 351 & - & 50 \\
\hline
\end{tabular}

Sumber: Dinas Kelautan dan Perikanan Kota Probolinggo (2010; 2011; 2012; 2013; 2014) 
Tabel 2. Produksi dan Nilai Produksi Perikanan Tangkap Laut di Kota Probolinggo, Tahun 2010 -2014

\begin{tabular}{cccc}
\hline No & Tahun & Jumlah (ton) & Nilai Produksi (Rp) \\
\hline 1 & 2010 & $36.087,80$ & 400.731 .035 .000 \\
2 & 2011 & $18.352,20$ & 222.010 .221 .500 \\
3 & 2012 & $10.200,89$ & 155.918 .443 .000 \\
4 & 2013 & $13.200,89$ & 177.031 .262 .000 \\
5 & 2014 & $15.989,33$ & 319.463 .134 .200 \\
\hline
\end{tabular}

Sumber: Dinas Kelautan dan Perikanan Kota Probolinggo (2010; 2011; 2012; 2013; 2014)

Tabel 3. Jumlah Kapal Motor di Kota Probolinggo, Tahun 2010-2014

\begin{tabular}{ccccccc}
\hline \multirow{2}{*}{ No } & \multirow{2}{*}{ Ukuran Kapal (GT) } & \multicolumn{5}{c}{ Tahun } \\
\cline { 3 - 7 } & Motor tempel & $\mathbf{2 0 1 0}$ & $\mathbf{2 0 1 1}$ & $\mathbf{2 0 1 2}$ & $\mathbf{2 0 1 3}$ & $\mathbf{2 0 1 4}$ \\
\hline 1 & $0-5$ & - & 27 & 27 & 27 & - \\
2 & $0-10$ & 126 & 72 & 108 & 90 & 90 \\
3 & $5-20$ & 13 & 67 & 40 & 40 & 34 \\
4 & $10-26$ & 37 & 41 & 54 & 67 \\
5 & $20-30$ & 154 & 104 & 132 & 156 & 83 \\
6 & $>30$ & $\mathbf{3 4 6}$ & $\mathbf{3 0 7}$ & $\mathbf{3 9 0}$ & $\mathbf{4 3 6}$ & $\mathbf{4 5 2}$ \\
& Jumlah &
\end{tabular}

Sumber: Dinas Kelautan dan Perikanan Kota Probolinggo (2010; 2011; 2012; 2013; 2014)

\section{Alat Tangkap menurut Permen KP No. 2/2015}

Permen KP No. 2/2015, diberlakukan dengan pertimbangan bahwa penggunaan alat penangkapan ikan Pukat Hela (trawls) dan Pukat Tarik (seine nets) di Wilayah Pengelolaan Perikanan Negara Republik Indonesia telah mengakibatkan penurunan dan mengancam kelestarian lingkungan sumber daya ikan. Kondisi ini salah satunya dapat dilakukan dengan melarang penggunaan alat penangkapan ikan trawls dan seine nets. Menurut Pasal 3, Permen KP No. 2/2015, alat penangkapan ikan trawls terdiri:

(1) Pukat Hela (trawls) terdiri dari:
a. Pukat Hela dasar (bottom trawls);
b. Pukat Hela pertengahan (midwater trawls);
c. Pukat Hela kembar berpapan (otter twin trawls); dan
d. Pukat dorong.

(2) Pukat hela dasar (bottom trawls) terdiri dari:
a. Pukat Hela dasar berpalang (beam trawls);
b. Pukat Hela dasar berpapan (otter traw/s);
c. Pukat Hela dasar dua kapal (pair traw/s);
d. Nephrops traw/s; dan
e. Pukat Hela dasar udang (shrimp trawls), berupa pukat udang.
(3) Pukat Hela pertengahan (midwater trawls) terdiri dari:
a. Pukat Hela pertengahan berpapan (otter traw/s), berupa pukat ikan;
b. Pukat Hela pertengahan dua kapal (pair trawls); dan
c. Pukat Hela pertengahan udang (shrimp trawls).

Penangkapan ikan Pukat Tarik (seine nets) menurut Pasal 4, Permen KP No. 2/2015:

(1) Alat penangkapan ikan pukat tarik (seine nets) yang terdiri dari:
a. Pukat Tarik pantai (beach seines); dan
b. Pukat Tarik berkapal (boat or vessel seines).

(2) Pukat tarik berkapal (boat or vessel seines) terdiri dari:
a. dogol (danish seines);
b. Scottish Seines;
c. Pair Seines;
d. Payang;
e. Cantrang; dan
f. Lampara dasar.

\section{Permasalahan Penggunaan Alat Tangkap Cantrang di Kota Probolinggo}

Aktivitas usaha penangkapan ikan dengan alat tangkap cantrang mencakup berbagai komponen. Komponen tersebut meliputi: aktivitas input produksi, distribusi dan pasca produksi, serta konsumsi. Aktivitas input produksi terdiri 
dari pengadaan operasional penangkapan seperti: alat tangkap, es, bahan bakar, keranjang, dan perbekalan. Aktivitas distribusi kegiatan penangkapan alat tangkap cantrang melibatkan tukang angkut, juru timbang, pedagang (eceran dan industri), serta konsumen. Aktivitas pascaproduksi adalah kegiatan pengolahan ikan hasil tangkapan (pengasinan dan industri surimi). Mekanisme aliran penangkapan ikan dengan alat tangkap cantrang, dapat dilihat pada Gambar 3.

Gambar 3 menunjukkan bahwa aliran penangkapan ikan merupakan jalur pemasaran hasil tangkapan nelayan cantrang yang melibatkan suplai operasional sebelum kegiatan penangkapan dilakukan, tukang angkut dari kapal ke TPI, serta juru timbang.

Mengacu pada Undang-Undang No. 7 Tahun 2016, tentang Perlindungan dan Pemberdayaan Nelayan, Pembudidaya Ikan dan Petambak Garam disebutkan bahwa nelayan adalah setiap orang yang mata pencahariannya melakukan penangkapan ikan. Selanjutnya ikan hasil produksi nelayan tersebut masuk ke pasar yang melibatkan pedagang pengumpul, pedagang besar dan pedagang pengecer sebagai lembaga-lembaga pemasarannya untuk sampai ke konsumen (Mubyarto, 1994; Hanafiah dan Saefuddin, 1983). Pemberlakuan Permen KP No. 2/2015, diduga akan mengakibatkan penurunan produktivitas hasil tangkapan. Identifikasi permasalahan penggunaan alat tangkap cantrang di Kota Probolinggo secara lengkap, dapat dilihat pada Gambar 4.

\section{Analisis Biaya Manfaat Dampak Pemberlakuan Permen KP No. 2/2015}

Pemberlakuan Permen KP No. 2/2015, memberikan arti bahwa pemerintah tidak melakukan tindakan apapun untuk mengatasi masalah yang terjadi, maka sejumlah kondisi baseline yang berhasil diidentifikasi ditunjukkan pada Tabel 4 dan Tabel 5. Konflik yang sering terjadi saat ini, bersentuhan dengan nelayan tradisional yang tidak menggunakan alat tangkap cantrang. Kusnadi (2002), menyatakan bahwa salah satu penyebab terjadinya konflik dalam masyarakat nelayan tradisional dengan nelayan modern, disebabkan juga oleh adanya perebutan sumber daya ikan. Hal ini dipertegas oleh pernyataan Kinseng (2007) bahwa konflik sosial antara sesama nelayan seringkali terjadi antara nelayan dengan tingkat kemajuan teknologi yang berbeda.

Berdasarkan Tabel 5, diketahui bahwa hasil identifikasi yang dilakukan menggambarkan nelayan sebagai kelompok yang menanggung risiko paling besar dengan adanya pemberlakuan kebijakan tersebut. Masyarakat nelayan merupakan salah satu golongan masyarakat

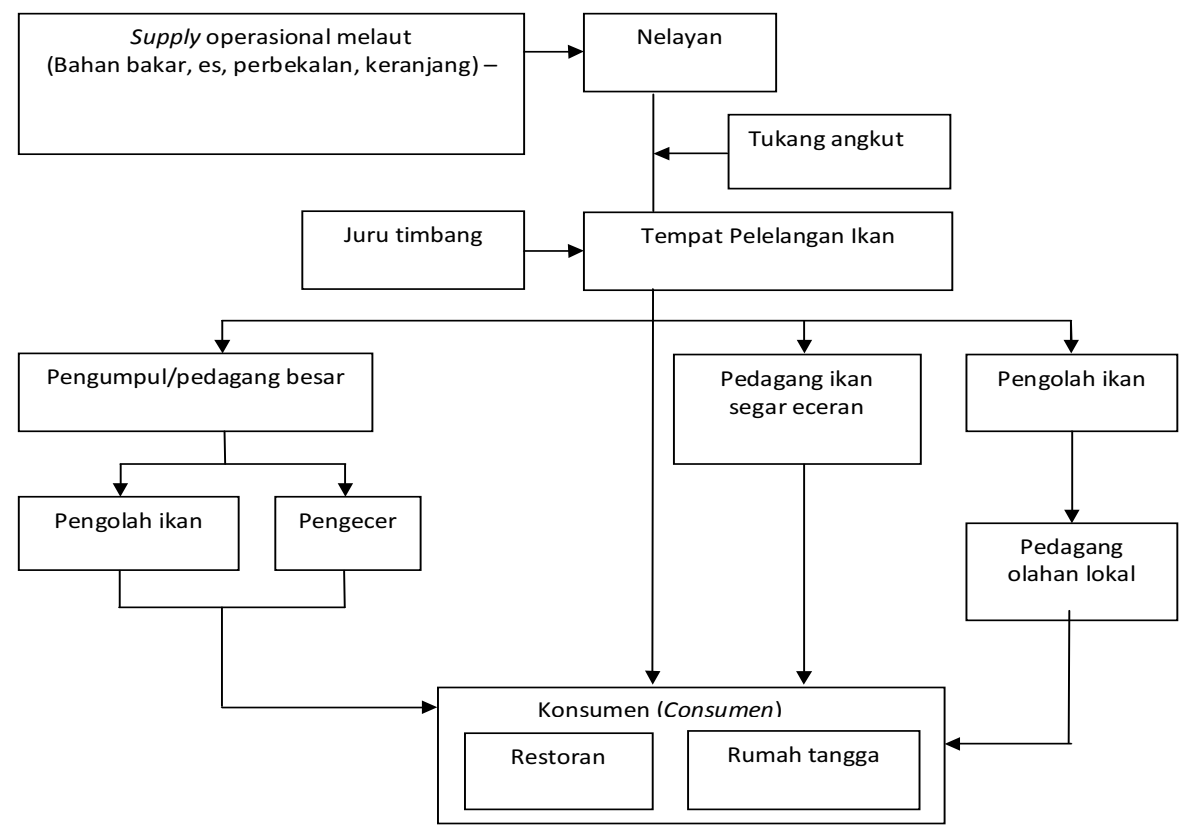

Gambar 3. Mekanisme Aliran Penangkapan Ikan Dengan Alat Tangkap Cantrang 


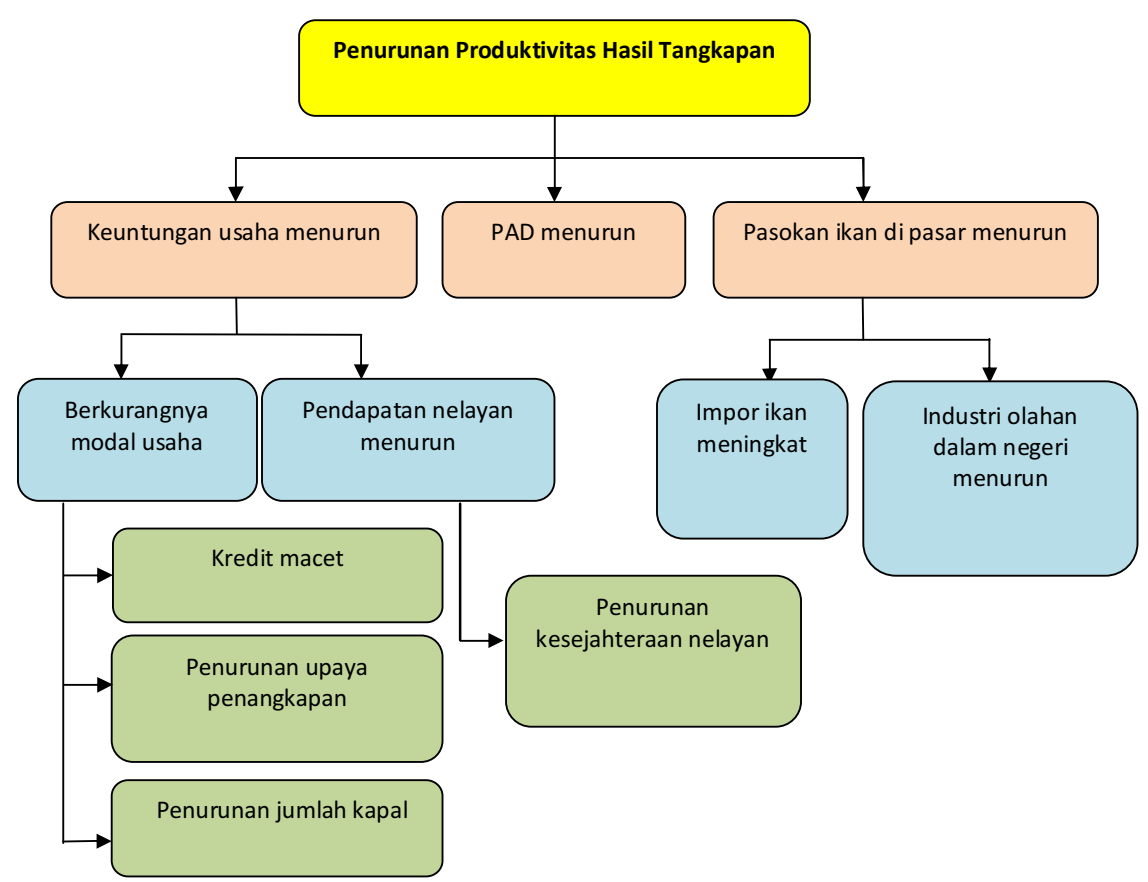

Gambar 4. Struktur Permasalahan Penggunaan Alat Tangkap Cantrang di Kota Probolinggo

Tabel 4. Analisis Biaya Dampak Permen KP No. 2/2015 Tetap Diberlakukan di Kota Probolinggo.

\begin{tabular}{|c|c|c|c|c|}
\hline No. & Pelaku & Indikator & Jumlah Kerugian & Keterangan \\
\hline \multirow[t]{4}{*}{1.} & Pemerintah & $\begin{array}{l}\text { Sosialisasi peraturan } \\
\text { dan pembuatan petunjuk } \\
\text { pelaksana }\end{array}$ & Rp. 52.460.300,-/tahun & $\begin{array}{l}\text { Data Dinas Kelautan dan } \\
\text { Perikanan Kota Probolinggo }\end{array}$ \\
\hline & & Penegakan hukum & Rp. 105.917.100,-/tahun & $\begin{array}{l}\text { Data Dinas Kelautan dan } \\
\text { Perikanan Kota Probolinggo }\end{array}$ \\
\hline & & Resiko politik (demo) & Rp. 0 & $\begin{array}{l}\text { Aksi damai dilakukan di } \\
\text { kantor DRPD (Februari 2015) } \\
\text { dan biaya demo bersumber } \\
\text { dari swadaya nelayan } \\
\text { cantrang }\end{array}$ \\
\hline & & Berkurangnya PAD & Rp. 30.000.000,-/tahun & $\begin{array}{l}\text { Berdasarkan Hasil } \\
\text { wawancara berkutangnya } \\
\text { PAD yang disumbangkan } \\
\text { oleh Nalayan cantrang tidak } \\
\text { terlalu signifikan }\end{array}$ \\
\hline \multirow[t]{7}{*}{2.} & $\begin{array}{l}\text { Nelayan } \\
\text { (juragan) }\end{array}$ & Penurunan pendapatan & Rp. 3.140.000.000,-/bulan & $\begin{array}{l}\text { Rata-rata pendapatan untuk } \\
\text { setiap kapal cantrang: Rp. } \\
20.000 .000 / \text { bulan dan totsl } \\
\text { jumlah total kapal } 157\end{array}$ \\
\hline & & $\begin{array}{l}\text { Kehilangan mata } \\
\text { pencaharian }\end{array}$ & 80 orang & - \\
\hline & & $\begin{array}{l}\text { Hilangnya nilai aset } \\
\text { produksi }\end{array}$ & Rp.78.500.000.000,- & $\begin{array}{l}\text { Jumlah kapal cantrang: } 157 \\
\text { (nilai kapal cantrang lengkap } \\
=\text { Rp. } 500.000 .000 \text { ) }\end{array}$ \\
\hline & & Berkurangnya tenaga kerja & orang & $\begin{array}{l}\text { Jumlah total } A B K+\text { tenaga } \\
\text { pengangkut+pedagang+ juru } \\
\text { timbang }\end{array}$ \\
\hline & & $\begin{array}{l}\text { Banyaknya juragan } \\
\text { bangkrut }\end{array}$ & 80 orang & $\begin{array}{l}\text { Data Dinas Kelautan dan } \\
\text { Perikanan Kota Probolinggo }\end{array}$ \\
\hline & ABK & Penurunan pendapatan & Rp. 2.198.000.000,-/bulan & 1 kapal cantrang: $10 \mathrm{ABK}$ \\
\hline & & $\begin{array}{l}\text { Kehilangan mata } \\
\text { pencaharian }\end{array}$ & 1.570 orang & $\begin{array}{l}\text { Data Dinas Kelautan dan } \\
\text { Perikanan Kota Probolinggo }\end{array}$ \\
\hline
\end{tabular}




\section{Lanjutan Tabel 4}

\begin{tabular}{|c|c|c|c|c|}
\hline No. & Pelaku & Indikator & Jumlah Kerugian & Keterangan \\
\hline & \multirow{2}{*}{$\begin{array}{l}\text { Pedagang } \\
\text { (Trader) }\end{array}$} & Penurunan pendapatan & Rp. 1.600.000.000,-/bulan & Hasil wawancara \\
\hline & & $\begin{array}{l}\text { Kehilangan mata } \\
\text { pencaharian }\end{array}$ & 200 orang & $\begin{array}{l}\text { Data Dinas Kelautan dan } \\
\text { Perikanan Kota Probolinggo }\end{array}$ \\
\hline & \multirow{2}{*}{$\begin{array}{l}\text { Juru timbang } \\
\text { (Interpreter of } \\
\text { weight) }\end{array}$} & Penurunan pendapatan & Rp. 208.000.000,-/bulan & Hasil wawancara \\
\hline & & $\begin{array}{l}\text { Kehilangan mata } \\
\text { pencaharian }\end{array}$ & 80 orang & 20 grup (setiap grup 4 orang) \\
\hline & \multirow{2}{*}{$\begin{array}{l}\text { Tenaga angkut } \\
\text { (Porter) }\end{array}$} & Penurunan pendapatan & Rp. 78.000.000,-/bulan & Hasil wawancara \\
\hline & & $\begin{array}{l}\text { Kehilangan mata } \\
\text { pencaharian }\end{array}$ & 60 orang & 10 grup (setiap grup 6 orang) \\
\hline 3. & $\begin{array}{l}\text { Perbankan } \\
\text { (Bank) }\end{array}$ & $\begin{array}{l}\text { Resiko kredit macet dari } \\
\text { nelayan cantrang }\end{array}$ & $\begin{array}{l}\text { Rp. } 13.056 .000 .000,-/ \\
\text { tahun }\end{array}$ & $\begin{array}{l}\text { Pinjaman drai Bank BNI } 46 \text { \& } \\
\text { Bank Jatim }\end{array}$ \\
\hline 4. & $\begin{array}{l}\text { Pelaku industri } \\
\text { (Industry) }\end{array}$ & $\begin{array}{l}\text { Keuntungan usaha } \\
\text { menurun karena } \\
\text { kurangnya pasokan bahan } \\
\text { baku dalam jangka pendek }\end{array}$ & Rp. 180.000.000/bulan & Hasil wawancara \\
\hline 5. & $\begin{array}{l}\text { Lingkungan } \\
\text { (Environment) }\end{array}$ & - & - & - \\
\hline
\end{tabular}

Sumber: Data Primer, 2015 (diolah)

Tabel 5. Analisis Manfaat Dampak Permen KP No. 2/2015 tetap diberlakukan di Kota Probolinggo.

\begin{tabular}{|c|c|c|c|c|}
\hline No. & Pelaku & Indikator & Jumlah Manfaat & Keterangan \\
\hline \multirow[t]{2}{*}{1.} & Pemerintah & Meningkatnya PAD & Rp. 0 & $\begin{array}{l}\text { Data Dinas Kelautan dan Perikanan } \\
\text { Kota Probolinggo }\end{array}$ \\
\hline & & Ketersediaan pangan & $28 \mathrm{~kg} / \mathrm{tahun}$ & $\begin{array}{l}\text { Data Dinas Kelautan dan Perikanan } \\
\text { Kota Probolinggo tahun } 2014\end{array}$ \\
\hline \multirow[t]{10}{*}{2.} & $\begin{array}{l}\text { Nelayan } \\
\text { (juragan) }\end{array}$ & Minimalisir konflik & Tidak berkurang & $\begin{array}{l}\text { Adanya kecemburuan sosial dan } \\
\text { pelanggaran wilayah kewenangan } \\
\text { penangkapan wilayah kota dan } \\
\text { kabupaten }\end{array}$ \\
\hline & & $\begin{array}{l}\text { Meningkatnya } \\
\text { perekonomian } \\
\text { nelayan kecil (non } \\
\text { cantrang) }\end{array}$ & Tidak terjadi & $\begin{array}{l}\text { Hal ini dikarenakan perbedaan } \\
\text { produktivitas penggunaan alat } \\
\text { tangkap }\end{array}$ \\
\hline & ABK & Minimalisir konflik & Tidak terjadi & $\begin{array}{l}\text { Hampir tidak pernah terjadi konflik } \\
\text { antar ABK }\end{array}$ \\
\hline & & $\begin{array}{l}\text { Meningkatnya } \\
\text { perekonomian } \mathrm{ABK}\end{array}$ & $\begin{array}{l}\text { Tergantung hasil } \\
\text { tangkapan }\end{array}$ & $\begin{array}{l}\text { Pendapatan ABK sesuai dengan hasil } \\
\text { tangkapan yang diperoleh }\end{array}$ \\
\hline & Pedagang & Minimalisir konflik & Tidak terjadi & $\begin{array}{l}\text { Tidak pernah terjadi konflik antar } \\
\text { pedagang }\end{array}$ \\
\hline & & $\begin{array}{l}\text { Meningkatnya } \\
\text { perekonomian } \\
\text { pedagang }\end{array}$ & $\begin{array}{l}\text { Tergantung jumlah } \\
\text { ikan yang dapat dibeli } \\
\text { pedagang }\end{array}$ & $\begin{array}{l}\text { Pendapatan tergantung daya } \\
\text { beli pedagang \& hasil ikan yang } \\
\text { didaratkan }\end{array}$ \\
\hline & Juru Timbang & Minimalisir konflik & Tidak terjadi & $\begin{array}{l}\text { Tidak pernah terjadi konflik antar juru } \\
\text { timbang }\end{array}$ \\
\hline & & $\begin{array}{l}\text { Meningkatnya } \\
\text { perekonomian juru } \\
\text { timbang }\end{array}$ & $\begin{array}{l}\text { Tergantung jumlah ikan } \\
\text { yang ditimbang }\end{array}$ & $\begin{array}{l}\text { Pendapatan tergantung jumlah ikan } \\
\text { yang ditimbang }\end{array}$ \\
\hline & $\begin{array}{l}\text { Tenaga } \\
\text { Angkut }\end{array}$ & Minimalisir konflik & Tidak terjadi & $\begin{array}{l}\text { Tidak pernah terjadi konflik antar } \\
\text { tenaga angkut }\end{array}$ \\
\hline & & $\begin{array}{l}\text { Meningkatnya } \\
\text { perekonomian juru } \\
\text { timbang }\end{array}$ & $\begin{array}{l}\text { Tergantung jumlah ikan } \\
\text { yang diangkut }\end{array}$ & $\begin{array}{l}\text { Pendapatan tergantung kepada } \\
\text { jumlah ikan yang diangkut dan } \\
\text { kapal cantrang langganan yang } \\
\text { mendaratkan ikan }\end{array}$ \\
\hline 3. & Perbankan & - & - & - \\
\hline
\end{tabular}


Lanjutan Tabel 5

\begin{tabular}{|c|c|c|c|c|}
\hline No. & Pelaku & Indikator & Jumlah Manfaat & Keterangan \\
\hline 3. & Perbankan & - & - & - \\
\hline 4. & $\begin{array}{l}\text { Pelaku } \\
\text { industri }\end{array}$ & $\begin{array}{l}\text { Meningkatnya } \\
\text { pasokan bahan baku }\end{array}$ & Rp. $180.000 .000 /$ bulan & $\begin{array}{l}\text { Bahan baku tergantung kepada } \\
\text { musim ikan (bahan baku untuk } \\
\text { industri yang tidak hanya diambil } \\
\text { dari hasil tangkapan nelayan Kota } \\
\text { Probolinggo) dan hanya mengambil } \\
\text { ikan sesuai dengan standar yang } \\
\text { ditetapkan perusahaan }\end{array}$ \\
\hline \multirow[t]{2}{*}{5.} & Lingkungan & $\begin{array}{l}\text { Meningkatnya } \\
\text { sumber daya ikan }\end{array}$ & $\begin{array}{l}\text { Meningkat dalam waktu } \\
\text { yang tidak singkat }\end{array}$ & $\begin{array}{l}\text { Perbaikan kerusakan yang terjadi } \\
\text { membutuhkan waktu yang tidak } \\
\text { sebentar (Hasil wawancara dengan } \\
\text { Dinas Kelautan dan Perikanan Kota/ } \\
\text { Kabupaten Probolinggo) }\end{array}$ \\
\hline & & $\begin{array}{l}\text { Terjaganya } \\
\text { kelestarian } \\
\text { lingkungan sumber } \\
\text { daya }\end{array}$ & $\begin{array}{l}\text { Sudah ada upaya } \\
\text { untuk mengembalikan } \\
\text { lingkungan sumber } \\
\text { daya }\end{array}$ & $\begin{array}{l}\text { Upaya ini belum dirasakan maksimal, } \\
\text { mengingat kerusakan yang } \\
\text { diakibatkan nelayan cantrang sudah } \\
\text { besar }\end{array}$ \\
\hline
\end{tabular}

Sumber: Data Primer, 2015 (diolah)

yang dianggap miskin secara absolut, bahkan paling miskin diantara penduduk miskin (the poorest of the poor) (Mukflihati, 2010). Berbagai studi menunjukkan bahwa kondisi nelayan, khususnya nelayan perikanan skala kecil di Indonesia berada pada tingkat marjinal (Kusnadi, 2000; Semedi, 2002; Budi, 2008).

\section{Implementasi Pelarangan Alat Tangkap Cantrang di Kabupaten Probolinggo}

Berdasarkan hasil kajian, diketahui bahwa opsi kebijakan untuk tetap memberlakukan kebijakan strategi yang tepat. Hal ini dikarenakan untuk menghindari pemborosan anggaran pembuatan peraturan dan menjaga kredibilitas pemerintah dalam membuat kebijakan. Disahkannya Permen KP No. 2/2015, mempunyai tujuan baik untuk melestarikan lingkungan ekosistem laut dan pesisir, serta meningkatkan kesejahteraan nelayan tradisional. Penerapan Permen KP No. 2/2015, dalam jangka panjang akan memberikan pemulihan ekosistem yang sudah rusak dan memberikan pemerataan pendapatan para nelayan Kota Probolinggo.

Paradigma ekonomi dalam angka yang dijadikan dasar mengelola sumber daya ikan selama ini, harus segera diseimbangkan dengan menekan berbagai kemungkinan dampak negatif. Paradigma ini dapat dihindari apabila permen
KP No. 2/2015, dilanjutkan pemberlakukannya. Menurut Supriatna (2008), pengelolaan sumber daya harus lestari dan berkelanjutan, sehingga manfaatnya dapat dinikmati generasi penerus. Pada konteks ini, pelaksanaannya perlu ditegaskan kembali dengan penambahan pasal terkait penerapan penghapusan penggunaan alat tangkap yang dilarang dan bentuk penerapan sanksi secara tegas.

\section{KESIMPULAN DAN IMPLIKASI KEBIJAKAN}

\section{Kesimpulan}

Strategi kebijakan yang dapat direkomendasi adalah tetap memberlakukan Permen KP No. 2/2015, dengan melakukan tindak lanjut:

- Penambahan pasal:

1. Tata cara penerapan penghapusan penggunaan alat tangkap pukat tarik (seine nets)/cantrang dilakukan secara bertahap.

2. Bentuk penerapan sanksi tegas kepada pelaku yang melanggar kebijakan Permen KP No. 2/2015.

- Mensosialisasikan dan menyelenggarakan pelatihan penggunaan alat tangkap ramah lingkungan (apabila sudah ada alternatif alat tangkap pengganti); 
- Membentuk tim khusus (KKP) yang bekerja sama dengan otoritas daerah untuk melakukan pendekatan secara sosiologis kepada nelayan yang terkena implikasi Permen KP No. 2/2015;

- Berkoordinasi dengan pemerintah daerah terkait, perguruan tinggi, organisasi nelayan, dan tokoh masyarakat, untuk melakukan simulasi serta pemantauan lapangan (kegiatan ini dimaksudkan untuk mengetahui: operasional alat tangkap Permen KP No. 2/2015 apakah memiliki status merusak atau tidak merusaknya). Hasil simulasi yang dilakukan nantinya harus dapat diterima oleh semua pihak;

- Membuat skema pembiayaan untuk membantu nelayan peralihan ke alat tangkap ramah lingkungan melalui organisasi nelayan atau kelembagaan koperasi nelayan;

- Berkoordinasi dengan pihak terkait (Kementerian Perhubungan/Syahbandar) untuk melakukan pengukuran ulang akte ukuran kapal ikan dan memfasilitasi penerbitan surat izin baru;

- Membuat petunjuk pelaksana yang jelas dan terarah terhadap pengaturan operasional alat penangkap trawls dan seine nets;

- Membuat sistem manajemen pengawasan yang ketat dan terpadu terhadap pelaksanaan Permen KP No. 2/2015, terutama terhadap perlindungan wilayah penangkapan bagi nelayan tradisional (bekerja sama dengan organisasi nelayan, institusi penegak hukum. Hal ini untuk menghindari konflik alat tangkap pada setiap provinsi/kabupaten/kota pesisir.

\section{Implikasi Kebijakan}

kebijakan tersebut diantaranya adalah dilakukannya revisi terhadap kebijakan yang sudah diberlakukan. Pengembangan usaha alternatif serta manajemen konflik yang baik perlu dilakukan. Hal ini sejalan dengan tujuan UU No. 7 Tahun 2016 pada pasal 3 poin a dan b yaitu: a) memberikan prasarana dan sarana yang dibutuhkan untuk mengembangkan usaha; dan b) memberikan kepastian usaha yang berkelanjutan. Selanjutnya kemandirian dan kesejahteraan nelayan di Kota Probolinggo dan daerah lain yang terkena dampak pemberlakukan Permen KP No. 2 Tahun 2015 dapat ditingkatkan.

\section{UCAPAN TERIKA KASIH}

Penulis mengucapkan terima kasih kepada tim penelitian yang terkait dengan topik kajian ini khususnya di lingkup Pusat Penelitian Sosial Ekonomi Kelautan dan Perikanan, Balitbang KP-KKP yang telah memberi dukungan financial terhadap penelitian ini.

\section{DAFTAR PUSTAKA}

Badan Perencanaan dan Pembangunan Nasional. 2011. Kajian Ringkas Pengembangan dan Implementasi Metode Regulatory Impact Analysis (RIA) untuk Menilai Kebijakan (Peraturan dan Non Peraturan) di Kementerian PPN/Bappenas. Biro Hukum Kementerian PPN/Bappenas - Bappenas. Jakarta.

Badan Pusat Statistik Kota Probolinggo. 2013. Kota Prbolinggo Dalam Angka 2013. Badan Pusat Statistik Kota Probolinggo. Kota Probolinggo

. 2014. Kota Prbolinggo Dalam Angka 2014. Badan Pusat Statistik Kota Probolinggo. Kota Probolinggo

2015. Kota Prbolinggo Dalam Angka 2015. Badan Pusat Statistik Kota Probolinggo. Kota Probolinggo

. 2016. Kota Prbolinggo Dalam Angka 2016. Badan Pusat Statistik Kota Probolinggo. Kota Probolinggo

Bailey, C. 1988. The Political Economy of Marine Fisheries Development in Indonesia. Indonesia No. 46 (Oct). Cornell Southeast Asia Program

Bambang, N. 2006. Petunjuk Pembuatan dan Pengoperasian Cantrang dan Rawai Dasar Pantai Utara Jawa Tengah. Balai Besar Pengembangan Penangkapan Ikan. Direktorat Jenderal Perikanan Tangkap. Departemen Kelautan dan Perikanan. Semarang

Budi, S. 2008. Kemiskinan dan Perlawanan Kaum Nelayan. Laskbang Mediatama. Malang

Dinas Kelautan dan Perikanan Kota Probolinggo. 2010. Informasi Data Statistik Perikanan Kota Probolinggo 2010. Dinas Kelautan dan Perikanan Kota Probolinggo. Kota Probolinggo 
2011. Informasi Data Statistik Perikanan Kota Probolinggo 2011. Dinas Kelautan dan Perikanan Kota Probolinggo. Kota Probolinggo 2012. Informasi Data Statistik Perikanan Kota Probolinggo2012. Dinas Kelautan dan Perikanan Kota Probolinggo. Kota Probolinggo

2013. Informasi Data Statistik Perikanan Kota Probolinggo 2013. Dinas Kelautan dan Perikanan Kota Probolinggo. Kota Probolinggo 2014. Informasi Data Statistik Perikanan Kota Probolinggo 2014. Dinas Kelautan dan Perikanan Kota Probolinggo. Kota Probolinggo

FAO. 1995. Code of Conduct for Responsible Fisheries. FAO. Rome

Hanafiah A.M dan A.M. Saefuddin. 1983. Tata Niaga Hasil Perikanan. UI Press. Jakarta

Keputusan Presiden (Keppres) Nomor 39 Tahun 1980, tentang Penghapusan Jaring Trawl (Pukat Harimau) di Perairan Jawa, Sumatera dan Bali. Ditetapkan di Jakarta, Tanggal 1 Juli 1980

Keputusan Menteri (Kepmen) Kelautan dan Perikanan No. 45 Tahun 2011 tentang Estimasi Potensi Sumber Daya Ikan di Wilayah Pengelolaan Perikanan Negara Republik Indonesia. Ditetapkan di Jakarta, Tanggal 3 Agustus 2011

Kinseng, R. 2007. Konflik Sumberdaya di Kalangan Nelayan di Indionesia. Sodality: Jurnal Transdisiplin Sosiologi, Komunikasi dan Ekologi Manusia. Vol. 01 No. 01. ISSN: 1978-4333. Hal 87 - 104

Kusnadi. 2000. Nelayan: Strategi Adaptasi dan Jaringan Sosial. Humaniora Utama Press. Bandung

2002. Konflik Sosial Nelayan. Kemiskinan dan Perebutan Sumberdaya Perikanan. LKIS, Yogyakarta

Marzuki. 2002. Metodologi Riset. Fakultas Ekonomi Universitas Islam Indonesia. Yogyakarta

Mubyarto. 1994. Pengantar Ekonomi Pertanian. Pustaka LP3ES. Jakarta

Muflikhati, I. 2010. Kondisi Sosial Ekonomi dan Tingkat Kesejahteraan Keluarga: Kasus di Wilayah Pasisir Jawa Barat. Jurnal IImu Keluarga (2-10)

Peraturan Menteri KP Nomor 2 Tahun 2015 tentang Larangan Penggunaan Alat Penangkapan Ikan Pukat Hela (Trawls) dan Pukat Tarik (Seine Nets) di Wilayah Pengelolaan Perikanan Negara Republik Indonesia. Berita Negara Republik Indonesia Tahun 2015 Nomor 31
Semedi, P. 2002. Close to the stone, far from the throne: The story of a Javanese community 1820s-1990s. Benang Merah. Yogyakarta

Supriatna, J. 2008. Melestarikan Alam Indonesia. Yayasan Obor Indonesia. Jakarta

Undang-Undang No. 7 Tahun 2016, tentang Perlindungan dan Pemberdayaan Nelayan, Pembudidaya Ikan dan Petambak Garam. Disahkan di Jakarta pada tanggal 14 April 2016 